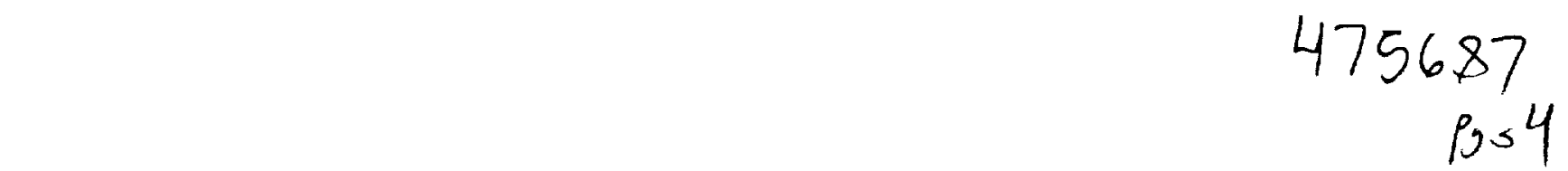

\title{
Measuring DIrectional Wave Spectra and Wind Speed with a Scanning Radar Altimeler
}

\author{
E. J. Walsh', D. Vandemark, C. W. Wright \\ NASA Goddard Space Flight Center, Code 972 \\ Laboratory for Hydrospheric Processes \\ Wallops Flight Facility, Wallops Island, VA 23337, USA \\ 303-497-6357, fax 303-497-6181, walsh@osh.wff.nusa.gov \\ 'presently on assignment at NOAA Enviroumental Technology Laboratory, Boulder, Colorado
}

\author{
R. N. Swilt, J. F. Scott, D. E. Hines \\ EG\&G Services, Inc. \\ N159, Wallops Flight Facility \\ Wallops Island, VA 23337, USA \\ 757-824-1019, fax 757-824-1036, swift@osb.wff.nasa.gov
}

Fig. I shows the geometry for the NASA Scanning Radar Altimeter (SRA). It transmits a 8-ns duration pulse at Ka-band $(8.3 \mathrm{~mm})$ and measures time of flight as it scans a $1^{\circ}$ (two-way) beam from left to right across the aircraft ground track. The most recent configuration determines the surface elevation at 64 points spaced at uniform angular intervals of about $0.7^{\circ}$ across a swath whose width is about 0.8 times the aircraft alutude. The system generates these raster lines of the surface topography beneath the aircraft at about a $10 \mathrm{~Hz}$ rate. In postflight processing the SRA wave topographic data are uansformed with a two-dimensional FFT and Dopplercorrected to produce directional wave spectra $[1,2]$.

The SRA is not absolutely calibrated in power, but by measuring the relative fall-off of backscalter with increasing incidence angle, the SRA can also determine the mean square slope (mss) of the sea surface, a surrogate for wind speed [3]. For the slope-dependent specular point model of radar sca surface scattering $[4,5,6)$, an expression approximated by is geometric optics form. for the relative variation with incidence angle of the normalized backscatter radar cross seclion would be

$$
\sigma_{m+1}=\sec ^{4} \theta \exp \left(-\tan ^{2} \theta / \text { mss }\right)
$$

where $\theta$ is the off-nadir incidence angle

If the logarithm of the range-corrected hackscattered power is plotted against $\tan ^{2} \theta$. the resulting curves approximate straight lines whose slope is inversely proportional to mss. But when a straight line is fitted through actual data. the resulting value of mssis is dependent on the span of ikidence angles used [3]. This problem can be eliminated by litting a quadratic to the data. The ratio of the linear to the quadratic coefficient is found to be determined by the mis, so a general model for relating niss to the non-Gaussian variation of backscaltered power with incidence angle can be determined. This nodel was used to determine the distontions expected in the SRA measurements of sea surface inpography to be used in the compulation of direcional wave specura.

The SRA had traditionally flown either upwave or downwave to acquire topographic data in the direction of most rapid variation. But during the 1998 hurricane season the SRA was installed on one of the NOAA P-3 hurricane hunter aircraft. The NOAA minimum height for the hurricane flights was 1500 $m$, significantly higher than the SRA had previously flown. And the flight patterns were such that the waves were generally propagating acruss the aircraft ground track rather that along it. The largest waves were generally observed near the edge of the swath during the hurricance flights.

A 3-dimensional simulation was camied out and it was determined that, even with a bearnwidth as small as $1^{\circ}$, wave tilt modulation of the radar cross section within the antenna footprint can cause a significant, systematic increase in the apparent magnitude of wave components in the cross-track direction. The higher the altitude and the shorter the wavelength, the larger the effect.

Fig. 2 shows the geometry for a $1500 \mathrm{~m}$ sircraft height and ocean waves of $50 \mathrm{~m}$ length and $1.25 \mathrm{~m}$ height. The two top panels indicate the SRA 8-ns pulse approaching the sea surfuce

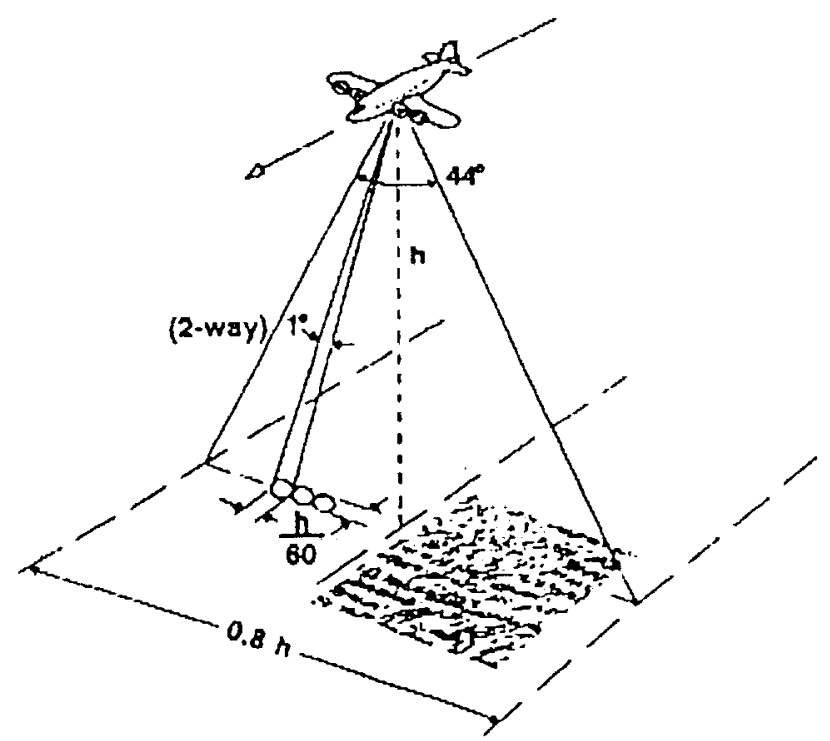

Fig. 1. NASA Scanning Radur Altimeter (SRA) geomery'. 


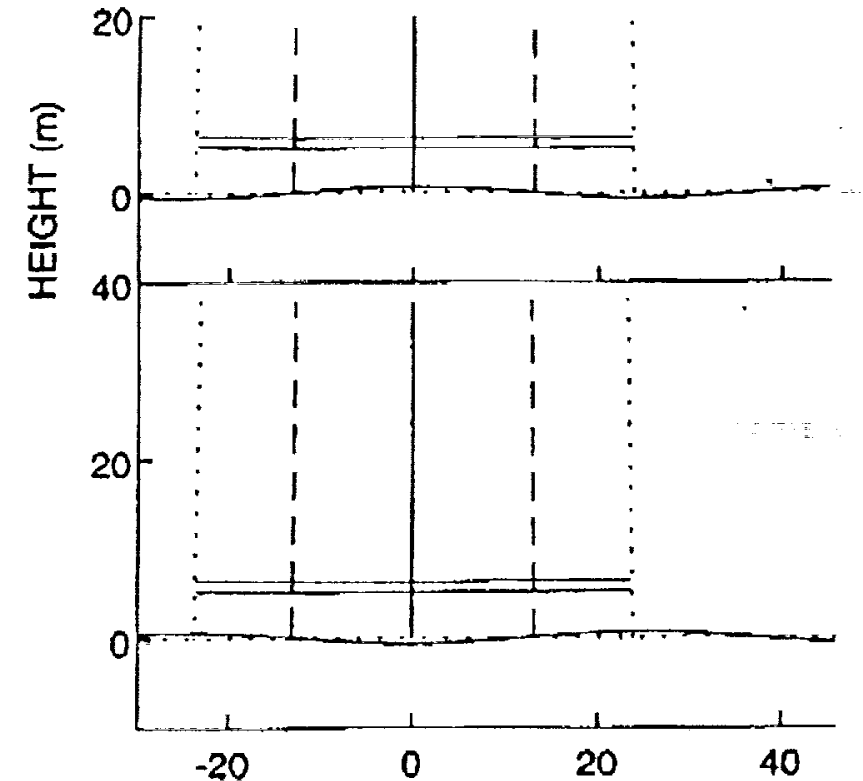

CROSS-TRACK OISTANCE FROM NADIR (m)

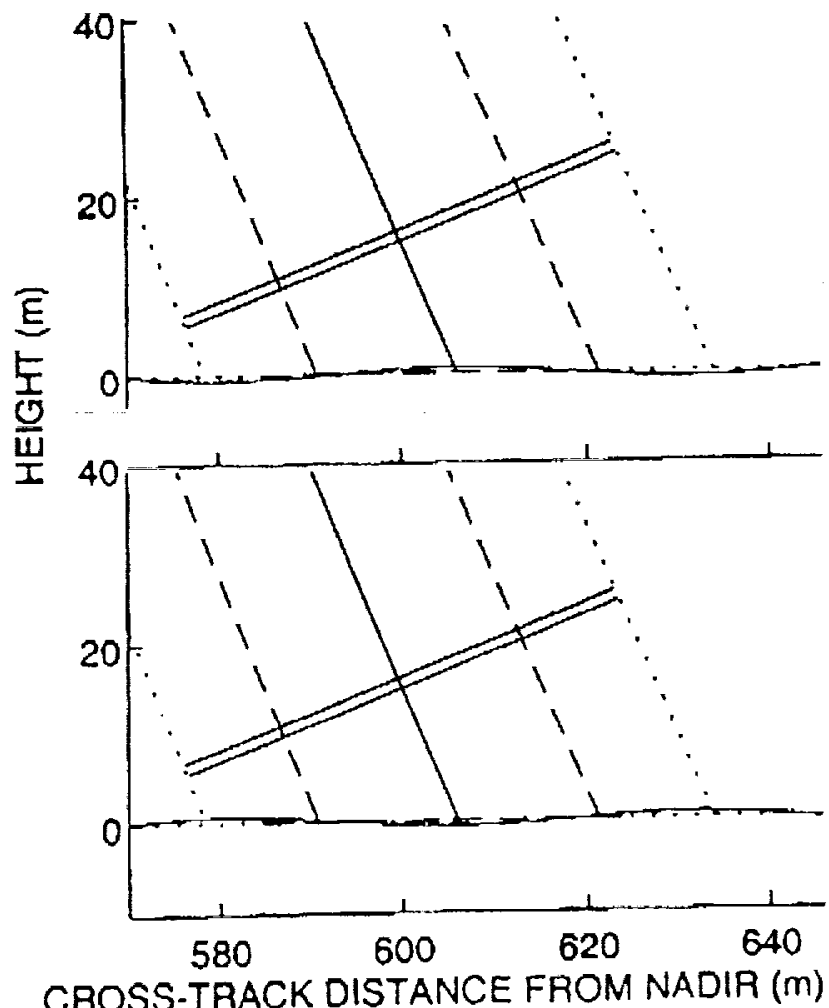

Fig. 2. SRA 8-ns pulse approaching sea surface from $1500 \mathrm{~m}$ height at nadir (top two panels) and $22^{\circ}$ off-nadic (hottom two panels) for waves of $50 \mathrm{~m}$ wavelength and $1.25 \mathrm{~m}$ height propagating in the cross-track direction. with the two-way half-power antenna beaniwidth indicated by the dashed lines and the 0.1 power beamwith indicated by the dorted lines. The solid line indicates the boresight, with a wave crest at the boresight in the top panel and a wave trough in the second panel. Spatial filtering by the antennis fuutprint would be expected for waves this short.

In the bottom two panels of Fig. 2, the boresight incidence angle is $22^{\circ}$ off-nadir, the nominal edge of the SRA swath. In this instance the simulation indicated that the measured wave height would actually be enhanced. The waves shown are propagating in the cross-track direction. and when the antenna boresight is at a crest (third panel). the near side of the crest backscatters morc power because the incidence angle is straller than for the far side of the crest. The centroid of the

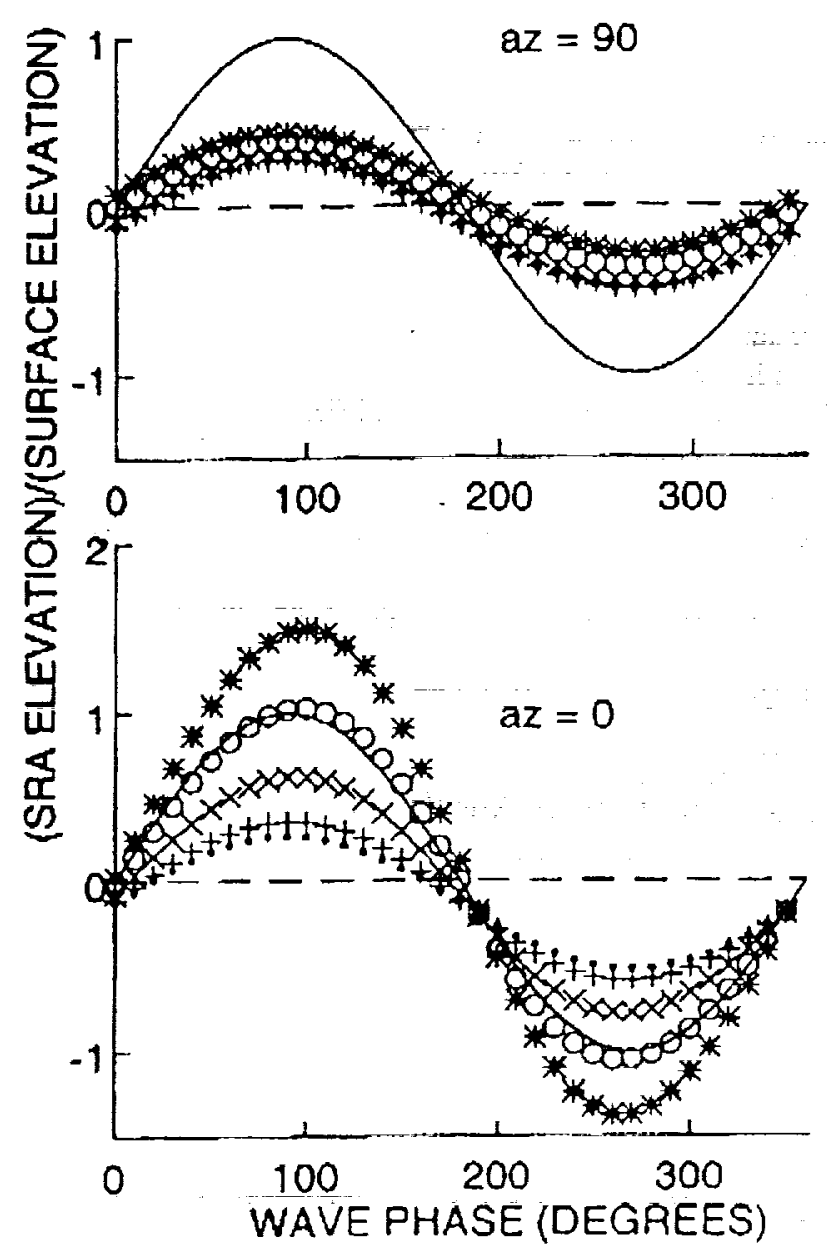

Fig. 3. Sea surface elevation meisured by the $S R A$ at nadir (.) and $4^{\prime \prime}(+), 8^{\circ}(x), 12^{\prime}(0)$, and $16^{\prime \prime}\left({ }^{*}\right)$ off-nadir, nomaliced by the peak of the sctual surface elevation for waves of $50 \mathrm{~m}$ length and $1.25 \mathrm{~m}$ height propagating in either the along wack direction (azimuth $=90^{\circ}$. top panel) or the cross-track direction (azimuth $=0^{\circ}$, bottom panel) for various phase angles of the wave train at the SRA antenna boresight. The assuned seil surface height variation is indicated by the solid sinusoidal curve. which has been normalized by its $0.625 \mathrm{~m}$ amplitude. 


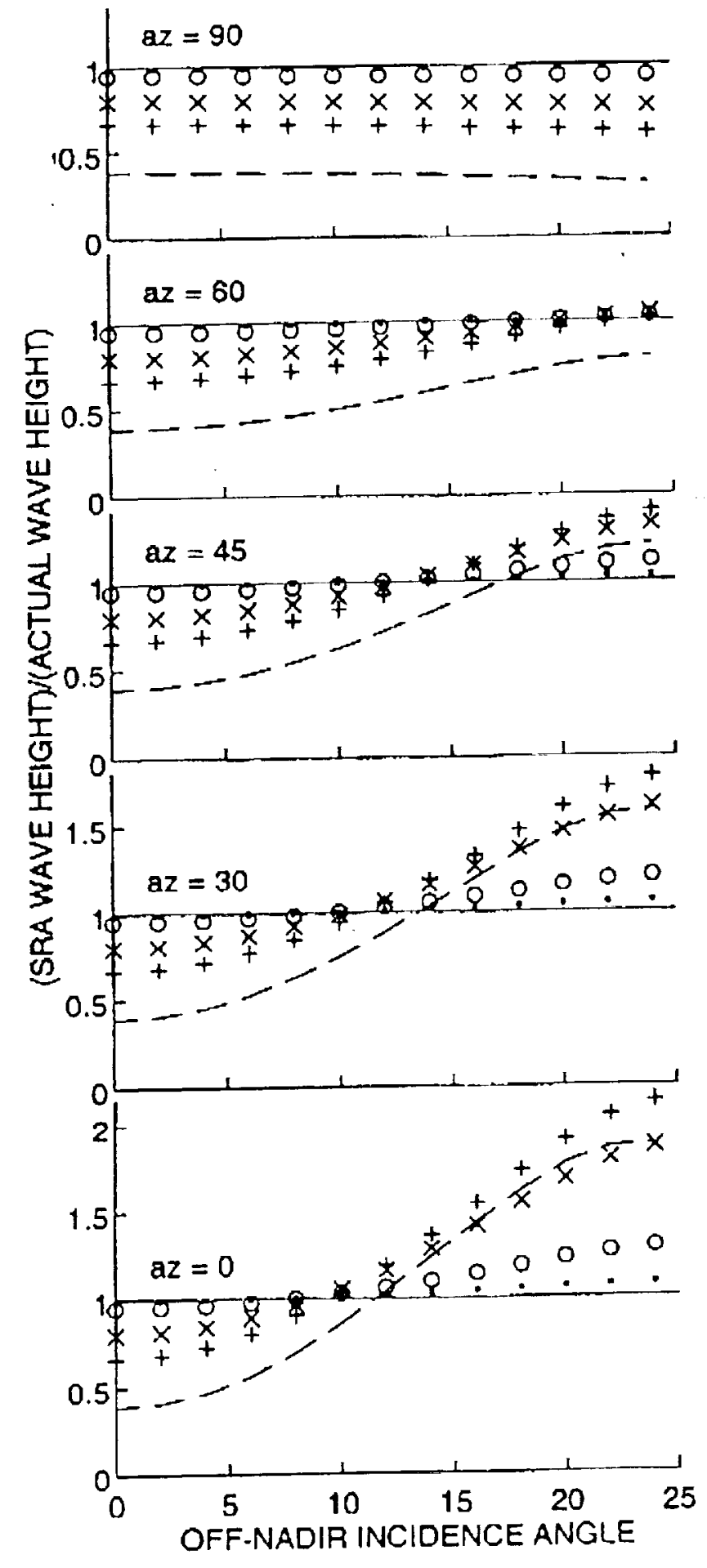

Fig, 4. Wave height measured by the SRA, nommilized by the actual wave height, for various propagation directions of the wave $t$ ain from alung-track (azimuth $=90^{\circ}$, top panel) to crossrack (azimuth $=\sigma^{\circ}$, botlom panel) for $\alpha$ can wavelengths of 50 $\mathrm{m}$ (dashed). $75 \mathrm{~m}(+) .100 \mathrm{~m}(\mathrm{x}) .200 \mathrm{~m}(0)$. and $400 \mathrm{~m}$ () for various incidence angles of the $S R A$ ancenna boresight. backscattered power is biased to shorter range. The short range is ascribed to the boresight angle and the resulting calculated crest position is higher. The reverse occurs at wave troughs (Fig. 2, buttum), where the erroneously larger range. ascribed to the antenna boresight. makes the truugh appear deeper.

Fig. 3 summarizes wave topography distortions for various phase angles of the ucean waves at the antenna boresight and various off-nudir angles for $50-\mathrm{m}$ waves propagating in the along-track (top panel) and cross-track (bottom pancl) directions. An inss of 0.08 was assumed, corresponding to -2.5 $\mathrm{m} / \mathrm{s}$ wind speed. The situation worsens al lower wind speed.

Fig. 4 summarizes (for mss $=0.08$ ) the variation of the ratio of measured to actual wave height for various ocean wave lengths and azimuth propagation directions relative to the crusstrack plane of incidence. All wave lengths are assumed to be 40 times the respective wave heights, for constant wave steepness appruximately comesponding to full developnxent.

At nadir, waves propagating in all directions have amplitudes reduced by the same amount. The reduction is over $60 \%$ for 50 $\mathrm{m}$ wavelength and negligible for $400 \mathrm{~m}$ wavelength.

For waves propagating in the cross-lrack direction. shorter waves are significantly enhanced at the edge of the swath. In general, the off-nadir incidence angle for the transition between wave amplitude reduction and enhancement depends on both the wavelength and the azimuthal direction of propagation.

Because the SRA simultaneously measures the baik kciutered power variation when it measures the wave topography, these distortions can be corrected in the directional wave spectra.

\section{REFERENCES}

[1] E.J. Walsh, D.W. Hancock, D.E. Hines, R.N. Swift, and J.Scott, "An ubservation of the diectional wave spectrum evolution from shoreline to fully developed," J. Phys. Occanogr., vol. 19, pp. 670-690, 1989.

[2] E.J. Walsh, L.K. Shay, H.C. Graber, A. Guillaume, D. Vandemirk, D.E. Hines, R.N. Switt, and J.F. Scott, "Observations of surface wave-curtent interaction during SWADE," The Global Amrosphere and Ocean System. vol. 5, pp. 99-124, Gordon and Breach Science Publishers SA. 1996.

[3] E.J. Walsh, D. Vandemark, C.A. Friche, S.P. Runs, D. Khelif, R.N. Swift, and J.F. Scott, "Measuring sea suriace mean square slop with a $36 \mathrm{GH} z$ scanning radar altimeter. J. Gouphys. Res., vol.103. pp. 12.587-12.601, June 1998.

[4] D.E. Barrick, "Rough surface scattering based on the specular point theory," IEEE Trans. Antennas Própag.. vol AP.16, pp. 449-454, 1968.

[5] D.E. Barrick. "Wind dependence of quasi-specular microwave sea scalter." IEEE Trans. Antennas Propng . vol. AP.22. pp. 135.136, 1974.

[6] G.R. Valenzucla. "Theories for the interaction of electromagnctic and oceanic waves - a review", Bound. Layer Meleor., vol. 13. pp. 61.85, 1978. 
